\title{
Recognition, Justice and Social Pathologies in Axel HONNETH's RECENT WRITINGS
}

Reconocimiento, justicia y patologías sociales en los trabajos recientes de Axel Honneth

\section{STÉPHANE HABER}

Universidad de Franche-Comté

\begin{abstract}
RESUMEN
Este ensayo discute el último libro de Axel Honneth sobre la cosificación (Verdinglichung, Frankfurt: Suhrkamp, 2005) y su relación con la teoría del reconocimiento avanzada por el mismo autor. El ensayo examina críticamente la nueva hipótesis de Honneth sobre las raíces existenciales del reconocimiento, y hace una comparación entre dos conceptos clave de la teoría crítica, la cosificación y la alienación, para argumentar la superioridad teórica de este último concepto.
\end{abstract}

Palabras clave: Honneth, reconocimiento, cosificación, alienación, teoría crítica.

\begin{abstract}
The paper discusses Axel Honneth's recent book on reification and its relation to Honneth's theory of recognition. It critically examines Honneth's hypothesis concerning the existential roots of recognition, and compares two classical concepts of social critique, reification and alienation, in order to argue for the superiority of the latter over the former.
\end{abstract}

Key words: Honneth, recognition, reification, alienation, critical theory.

In just over a decade, between Struggle for Recognition (1992) and Reification (2005), Axel Honneth has deeply modified the direction of his "theory of recognition." Any attempt to analyze and evaluate this paradigm of social philosophy, discussed everywhere today, must take this modification into account.

In Struggle for Recognition, Honneth's initial ambition was to make a sociological contribution: to propose a non-utilitarian explanation for the motivations of certain social struggles characteristic of the past as well of the present. His aim was to offer such an explanation without falling into the classical difficulties of a "politics of identity." The basic assumption he elaborated is that these struggles, which seem to be oriented solely towards gaining a more advantageous distribution of riches and power, in fact have other stakes which are more difficult to seize, but which are essential not only from the subjective perspective of the actors, but also objectively. These stakes are related to the preservation of the conditions of what one may call the consciousness of the dignity of a social group -the consciousness of its value, of its importance, and of its respectability. 
From an anthropological perspective, Honneth wanted to show that dignity, understood in the above sense, finds its support and even its natural environment in the relationships of recognition, in the consciousness of its own value. A social group cannot obtain dignity, confirm it durably or find stimulation for its expression unless it meets with the approval of other social groups. For "consideration" to be ensured and stabilized, one needs institutional warrants and cultural representations that can be transformed according to new requirements which manifest themselves as a result of social movements and political struggles. According to this hypothesis, behind social conflict one must discern something else, something fully positive, namely, the search for recognition and, perhaps, even a quest for reciprocity. Thus, the claims (for new rights, for a redistribution of riches, for cultural contents less affected by subordination, etc.) expressed in a legitimate social conflict must also be generously understood as possible positive contributions to the establishment of better relations and recognition between human beings.

Finally, Honneth wanted to root his sociological and anthropological reconstruction of struggles for recognition in a certain psychological approach. He assumes that there exists a kind of continuity or of kinship between the needs of recognition specific to social groups, which express themselves through socio-political conflicts, and those specific to individuals. This continuity presumes that the possibility of carrying out actions by oneself, whatever their particular contents is always conditioned by a positive relationship to oneself (i.e. self-confidence, self respect, self-esteem) which is made possible by others' recognition of the individual. In this sense, the most significant institutions must be conceived as a means through which this intersubjective support is fixed and extended to social life as a whole.

\section{THEORETICAL INNOVATIONS IN REIFICATION}

In Honneth's recent work, Reification: A Study in Theory of Recognition, none of these three aspects of the former theory are denied or even modified. However, the author seeks to show, in a way which can be described as non-Hegelian, that there is another, more primordial level of recognition which is not immediately linked with social and cultural institutions and is less dependent on the phenomenon of social struggle. The background of this surprising evolution is clearly a political one: in the era of global neo-liberalism, social movements that pursue the extension of institutional conditions of recognition are not at the core of our historical present. In other words, one can no longer rely on "History" as the medium for struggles for recognition. It seems more promising to work out a philosophical interpretation which, while remaining consistent with the important theoretical results obtained within the Hegelian framework, makes it possible to express in a direct way certain pathologies inherent or strongly connected to this new phase of capitalism. With this intention, Honneth maintains his initial intuition -to generate a critique by showing how relations of recognition are distorted in a given practice- while also seeking to demonstrate that there exist relations of recognition which precede those analyzed in Struggle for Recognition. The contemporary evolution of capitalism is precisely 
what negatively affects these fundamental preconditions of a non-pathological human experience of the world. Within this new framework, Honneth conceives of recognition from the point of view of those who exert it and no longer from the point of view of those who profit from it. Thus, recognition becomes a subjective and, so to speak, pre-social operation rather than a social state or the result of a social process which only concerns the individual secondarily.

With the term "recognition," Honneth now refers to the subjective attitude towards a given object (elements of the internal or of the external world) by which this object receives detailed attention, is constituted as something interesting or of value, as something one understands and upon which one feels emotionally dependent. Thus, to recognize it is to feel a kind of sympathy by which the object wins a certain consistency, thereby giving birth to the need to know it. With this new definition of recognition, which seeks to be more fundamental than the former, Hegelian one, the antonym of recognition is no longer contempt, exclusion, or humiliation (which reveal the inadequacy of social institutions with respect to the individual legitimate needs of recognition). ${ }^{1}$ Rather, indifference, blindness and ignorance are now opposed to recognition, and appear as the preconditions for the installation of a simply instrumental relation, a cold manipulation and hostility, towards the objective world. Philosophical reflection no longer represents the interests of those who are victims of the social conditions marked by a deficit in public structures of recognition. More uniquely, philosophical reflection emphasizes the point of view of the agents who are unable to recognize what must be recognized if one wants to authentically be a subject. Indeed, the center of gravity in Honneth's later theoretical construction lies in a kind of psychology which is deeper than the pratico-emotional circumstances favorable to the realization of the self and is more interested in the operations without which reality would not be "revealed" (in a phenomenological sense) and the object would be irrevocably missed.

Let me briefly examine the author's method. In Reification, Honneth (1) begins by asserting a very general thesis, which is of an epistemological nature: we do not understand, he says, an object or a situation without taking part in it in some manner, without a kind of existential engagement, without an active demonstration of concern or interest (chapters 1 and 2). Then (2), he operates a clear -and, in my opinion, much too brutal-inter-subjective redefinition of this argument: he claims that it is the relationship with others that constitutes the fundamental (structural) and the first (chronological) model of the movement by which we are bound to know a being and to recognize it (chapters 3 and 4). Before the "Hegelian" recognition of persons as legal and social entities sets in, I must already recognize others as being capable of having intentions and affections, which is a relatively autonomous phenomenon. The key-argument in favour of this new thesis is that, from an ontogenetic point of view, understanding of others constitutes the condition of possibility for knowing

1 Honneth himself underlines that at stake in this second kind of recognition is "a more elementary form of recognition than I have dealt with in my previous work on the topic." From now on, he writes, "I take it as given that this 'existential' mode of recognition lies at the bottom of all other, more substantial forms of recognition, through which the properties or capacities of others are affirmed" (2005: 60). 
the world. Finally (3), in what amounts to a radically new development with respect to Struggle for Recognition, Honneth extends this new model of recognition to the relationship with oneself (chapter 5). He claims that to recognize oneself means to take an interest in one's own emotions and desires, to adopt a non-distorted relationship with oneself. Thus, we learn that self-realization, conditioned by a positive relationship with the self, is not entirely determined by the approval of others. In fact, self-realization presupposes a preliminary self-constitution of subjectivity, which necessitates that one takes a sympathetic stance towards oneself, a notion that is more archaic than the psychological phenomena expressed in self-esteem, self-respect and self-confidence. The concept of reification, drawn from Lukács' work, allows Honneth to re-inject a socio-critical element into this new theoretical model (chapter 6). Reification, i.e. the fact of treating someone like a thing that is easy to handle, as though it possessed a concrete nature, is identified by Honneth as the condition of forgetting what we owe to the process of recognition. In other words, when under the pressure of certain social circumstances, recognition of others (or of oneself) is missing, neglected or repressed, increases the probability that we will establish a detached or purely instrumental relationship to others, to the social group and to oneself. This is what Honneth, extending Lukács's own critical intentions in employing the concept, now calls "reification." Racism, the systematic handling of persons and groups, the consumerist instrumentalization of personal and bodily properties, and the generalization of strategic behaviour in society, constitute crucial historical examples of reification. According to the spirit, if not according to the letter of Honneth's last work, one may say that reification causes or allows for the proliferation of this kind of phenomena and constitutes one of the main traits of the current historical period, of course largely explainable by the evolution of neo-liberal capitalism.

\section{EITHER REIFICATION OR ALIENATION? CRITICAL REMARKS ON HONNETH}

The major philosophical shift occasioned by Reification is its relativization of the theory of justice. The objective is now to work out a theoretical framework which allows for a direct apprehension of social pathologies - pathologies which do not only appear to be failures in a moral sense, but which must be grasped as instances of essential deformations of certain decisive conditions of the human experience. ${ }^{2}$ Of course, the lived injustice explored in

2 In his 1994 essay on "Pathologien des Sozialen. Tradition und Aktualität der Sozialphilosophie" (2000: 11-69), Honneth claimed that his first theory of recognition, the one conceived as a theory of justice, was strong enough to carry out the programme of a theory of social pathologies. By showing how certain general conditions of any human successful life are suppressed in failing or distorted relations of recognition, one implicitly joined the Marxist project of an analysis of social pathologies and their sources (in opposition to a simple framework allowing to think injustice as failure compared to moral standards or to standards of moral form). The philosopher still adopts this position in his discussion of Nancy Fraser's "antipsychologism" (Fraser, Honneth, 2003: 148-159): there are experiences of injustice, in fact of humiliation and contempt, which are not only mere effects or expressions of injustice, but which constitute a very moment of a true concept of injustice. In this sense, a theory of justice should naturally be articulated with our taking into account the suffering and pathologies caused by irrational social institutions. In the last pages of Reification (2005: 106-107), it seems that the philosopher radicalizes this position. By relativizing the liberal obsession with "neutrality," 
Struggle for Recognition was already of the order of social pathology. ${ }^{3}$ However, there are many aspects of social pathology that cannot be conceived as effects of injustice. They are something other than motivational resources of rationally justifiable social struggles. As Honneth's new position strongly asserts, by analyzing these different aspects of social pathology, we may reach a level far deeper than theories of justice and injustice have traditionally explored.

In my view, this recent evolution of Honneth's though offers fruitful opportunities while, at the same time, revealing certain philosophical difficulties. My critical remarks will try to make plausible the claim that this evolution constitutes a decisive incentive to articulate both the problematic of recognition and an anthropology of alienation, which I think is unavoidable when formulating a consistent interpretation of social pathologies.

However, by privileging the problematic of reification over the problematic of alienation (however close and historically associated these two may appear), Honneth is forced into offering much too narrow of a space for his own critical theory. In other words, because he is reasoning on the basis of a dualism of recognition and reification, he restricts the specific approach to the pathological phenomena which his own project presupposes. The principal indication of this narrowness is that if the hypotheses found in Reification were correct, then the theory of "major" pathologies, having as its only resource the above mentioned dualism, would seem far too poor for the conceptual contents and empirical objects found in the theory of justice and injustice. This imbalance would be embarrassing. For this reason, I would like to highlight some problems arising from the dualism of recognition and reification. This dualism shows its weakness when it is understood as the core of a correct apprehension of the social pathologies which are not reducible to injustice.

I will start with what appears to be something of secondary importance in Reification. It concerns a short section of the text in which Honneth rejects the possibility of the recognition of nature, or more precisely, of those non-human beings which are often said to belong to nature. ${ }^{4}$ According to Honneth, it is only in an indirect way that the reification of nature and "natural" beings can be conceived as a pathological phenomenon. It is not as an individual or as a subject that I lose something when I scorn or I plunder nature, or when I remain unaware of the world. In these instances, I am only acting as a social being. Only then, explains Honneth, does the way in which I recognize others, the way in which I attach importance to them and to their interests, reveal its partiality, its narrowness.

philosophical reflection claims for itself a quasi-ethical project able to determinate the criteria which make it possible to evaluate forms of life. More precisely, philosophical reflection should assume, says Honneth, the task of describing for themselves and in their specific structures the deformations by which social phenomena can be described as intrinsically irrational or, simply, as bad.

3 See Struggle for Recognition, Ch. 6. Honneth already insisted in these pages on the fact that the non-satisfaction of expectations related to recognition does not only constitute an obstacle for one's self-realization. Rather it must be understood as a direct attack against the integrity of the person that can be thought according to the model of physical wound or disease.

4 Honneth, 2005: 75-77. 
Indeed, "to recognize" others is, normally, to admit by default the importance of what gives rise to their interests and the significance of their thoughts and their actions. It is only through this derived meaning that the reification of nature and of natural beings proves to be problematic. Strangely enough, through this analysis, Honneth joins ranks with the traditional position of transcendental philosophy according to which there is nature (and also world) only for us and by us. Given this assumption, both from an anthropological point of view as well as from a moral point of view, we would not be making a mistake if we viewed natural beings in a purely objectifying way. This kind of "inter-subjectivist dogma" -the idea that we owe to others what we are, that is, the idea that our relations with others determine and carry all the other relations which define a subject- turns out to be embarrassing here. It leads us to conceive the world as made up of objects which, dead in themselves, are discovered only when we borrow another's perspective. Apart from this phenomenological difficulty, one may find it disappointing (even if it is not absurd or contradictory) that, from the beginning, a theory of social pathologies relativizes to such an extent the environmental problem and, more generally, decides not to address the issue of damages inflicted upon internal and external nature. In the last instance, such a theory proves unable to give any sense to the ignorance of objective reality (what the classical philosophers used to call "illusion").

To begin to clarify the reasons for this feeling of disappointment, it is necessary to begin by admitting that the instrumental relationship to natural beings, and to other living beings in particular is, in many of its concrete modes, inherent to many common human practices. Most of the time, it is necessary to eat meat, to be protected from harmful species, to use animal force, etc. On the other hand, contrary to Honneth's position, one can argue that we reify living beings -and this represents only one possibility inherent in the usual instrumental relation to the world- when we systematically fail to understand the fact that natural beings carry essential properties of animated beings, to such a degree that this makes us insensitive to certain motivations which, normally, we would view as morally signifying or, at least, as morally problematic. Let us admit, for instance, that it is legitimate to breed cows and salmon, even on an industrial scale, in order to organize the massive consumption of their flesh. This does not suggest that the way in which they live and are killed, as well as the very principle of this breeding and its extension, is beyond criticism. In fact, a "reification" of these animals would begin the moment when a minimal sensitivity to this problematic character is abolished, when the routine would defeat perplexity. We would become indifferent to them, and, finally, it would become unintelligible and unimaginable to us that they could seek to live a life appropriate to their own nature (as Stoics used to say) and that they can suffer (as Bentham used to say) as do all animated beings (in opposition to material objects). In this case, they would cease to be anything to us but "things".

The specificity of living beings (which can be qualified in some way as "natural," even though this does not imply that we simply ignore the fact that most animals are compounds of naturality and artificiality) shows that it is possible to make reification something more dramatic than merely a result of the failure to remember certain primitive interests for the Similar and for the Identical. From a non-inter-subjectivist point of view, reification seems 
intertwined with a distorted perception, with a fundamental error of orientation vis-a-vis beings. This point of view would make possible a stronger concept of reification which, rooted in a phenomenology of perception, would go further than that which contradicts the original movement of recognition and would perhaps make it more capable of seizing certain central social pathologies (concerning the relation to nature and to the world in general) which Honneth does not mention. From this point of view, reification would not only come from the fact that someone is unaware of the world-disclosing role of recognition, basically and mainly conceived as oriented towards human persons. Reification would not only be opposed to recognition (an empathic and projective movement by which I find interest in a being, ego or alter ego, I perceive), but, more radically, it would be opposed to something that is often - but not always and not necessarily - embedded in this recognition: comprehension, i.e., the capacity to determine that a particular being belongs to a certain category (living beings, etc.), and therefore the capacity to make correct distinctions between things, animal and human agents for example. ${ }^{5}$ As such, reification would have, as its practical correlate, a limited subjective life because the relationships that a subject maintains with its environment then misunderstands Being, the world, and itself as a consequence. If this misunderstanding takes the shape of a durable disposition, it becomes philosophically interesting to conceive of it as an effect of alienation.

One may go further. One can show, without adopting a point of view too far removed from that of Honneth's work that not even a stronger concept of reification (a non-intersubjectivist one) could constitute a solid basis for a theory of social pathologies suggested by the example above. For further illustration let us examine the problem of capitalism. Undoubtedly, Honneth does not intend to reduce the critique of capitalism - even less the critique of the present age in general - to a critique of reification. The concept of reification

5 It seems possible to mobilize the theory of perception found in authors like Husserl and especially MerleauPonty to apprehend things in a way quite different than Honneth's, who reasons on the basis of the dualism of involved concern and cold reification. To perceive is certainly not to observe phenomena in a purely detached manner, but - and Honneth is misleading when he wants to make us take this step forward - it is not yet to be sympathetically implied in a total situation in Dewey's or Heidegger's sense, see Reification, chapter 2. As illustrated by the example of vividness of atmospheric and symbolic elements in vision (clearly, the fact that to see red objects, in certain cases, provokes a kind of tension that does not exist in the contemplation of a blue sky), perceiving should rather be conceived as an experience by which a living organism understands data in its environment while placing itself in unison with it, by improvising a way of corresponding to it and of answering it (see, e.g., Merleau-Ponty, 1999: 243). Even if a kind of participation is at stake in both cases, the term "recognition" (or one of the terms Honneth connects to it, such as those of involvement and concern) seem too strong to indicate this lighter, more discrete, but perhaps more decisive "understanding." Besides, the latter does not have as its opposite analytical and instrumental reification, but perceptive error. One could say that it is only in the perception of facial mimicry and the animated movement (e.g. to seize the movement of escape of an animal or the finality of a gesture) that "understanding" takes a richer form, with more complex emotional and cognitive resonance, which makes it possible to reintroduce without violence in this connection the vocabulary of "sympathy." Thus, reification can be reintroduced as a phenomenon by which an absence of sympathy with living beings leads to a radical non-comprehension of them, to an ignorance of their nature. 
cannot be relied on in the way that Lukács relied on it, that is, as the single concept upon which to build a critical theory of modern society, thereby assigning it univocal content.

In his recent writings, Honneth analyzes the way in which the emancipatory resources of the post-war period in western countries were in fact quietly drawn in a new direction. For example, the growing valorization of the individual in culture and in society paradoxically fed neo-liberal ideologies which falsely see in the decay of social and public protections a phenomenon that favours individual autonomy. ${ }^{6}$ However, according to Honneth, the critique of reification is intended to constitute one of the major resources in both the analysis of neo-liberal capitalism, and the explanation of the social forms of individualization that accompany it. Illuminating the effects of commodification and universal instrumentalization, the concept of reification would supplement the theory of ideological "paradoxes" of the neo-liberal period. The critique of reification would allow us to extend the traditional critique of the calculating ethos related to the modes of control functionally adjusted with capitalism to an analysis of the concrete effects of this ethos on the individual's life. Taken in and of itself, this extension would be enough to elucidate the distance that has been covered since Struggle for Recognition. In that work, the critique of capitalism, which was largely implicit and not very specific, seemed to be anchored in a Durkheimian point of view. Honneth suggested that the economic injustices related to the capitalist mode of production deplete the normal conditions of individual protection, causing people's achievements to be bound within the framework of a forced division of labour, resulting in them being either ignored or underestimated. In Reification, contemporary capitalism is analyzed in somewhat greater detail and appears to promote conducts vis-a-vis oneself and vis-a-vis others which we have good reason to find threatening when compared to the minimal requirements of integrity found in personal and interpersonal life. ${ }^{7}$ A striking example of this, according to Honneth, is the structure of job interviews, where candidates put themselves in situations which reveal the instrumental and reifying relationship they have with themselves. ${ }^{8}$ It is this same model of relationship to oneself that can overflow, according to Honneth, into the world of interpersonal relationships. Today, this is evident in the practice of advice giving and taking, which is contaminated by the instrumental values of "coaching," and in love relationships, similarly contaminated by the proliferation of internet dating websites.

Honneth, 2002: 141-158.

No doubt that Honneth remains far from the economist approach that would seek to explain every manifestation of reification by "capitalism" (see, on this subject his critique of Lukács, 2005: 95-98). But apparently that does not prevent him from admitting that the current progress of reification is primarily explainable by the pressure exerted by the dynamics of capitalism, as the importance he attaches to commodification in general and to the crisis of the world of work shows (ibid, 103-106).

8 See Honneth, 2005: 105: “While formerly the function of job interviews was, generally speaking, to check by way of written documents or proofs of competence whether a candidate was qualified for a specific activity, now the sociology of work informs us that recruiting often takes on a very different character: job interviews increasingly resemble sales pitches because they require the job candidate to perform his future commitment to the job in the most convincing and dramatic way, instead of reporting on his or her qualifications which have been already acquired. This displacement of the object of attention from the past to the future forces the candidate to adopt a perspective in which they conceive of their own attitudes and feelings towards their work as 'objects' that they will have to produce in the future." 
The examples given by Honneth suggest a simple remark. The theory of reification, no matter how much it intends to contribute to the critique of contemporary ideologies of capitalism, not only seems to be separated from any given economic conceptual framework, but appears to remain outside of the world of work. ${ }^{9}$ Honneth's theory of reification enters neither the offices nor the factories, thereby distinguishing itself from the Marxist tradition, and encouraging abstraction from the sociology of work. Perhaps what explains the need for this abstraction is the weak analytical and critical content of this theory and of its recognition-reification dualism. In neo-capitalism, Honneth explains, individuals are constrained to adopt manipulative and coldly instrumental attitudes towards others and themselves. Even emotional life and intimate relationships change under the pressure of competition and personal success. All this is true and interesting. The system constituted by the theory of "paradoxes" and by the theory of reification proposes extremely rich outlines for Critical Theory. However, if one thinks about what would be required for a specific critical analysis of contemporary capitalism, joined with a true analysis of the experiences of personal limitation, bodily and psychic discomfort and individual suffering, Honneth's system would be insufficient. After all, we must remember that these two requirements are constitutive of Honneth's philosophical project.

One might like to say, intuitively, that this approach should be articulated through concepts more precisely adjusted to the explanation and the description of people's work conditions, which would take into account the specifically contemporary "injustices" that, in fact, are also radically pathological in Honneth's meaning. One might like to say that it should be necessary for a theoretical construction that claims to reflect, more than others, the contemporary evolutions of capitalism, to evoke and to interpret these unpleasant aspects of our present. Apart from these considerations, the lapse of memory concerning the psycho-sociological centrality of work, unfortunately encouraged in Frankfurt by Habermas, remains in force. If these conditions are not fulfilled, a theory of reification dedicated to the critique of symptoms rather than to the pathological facts themselves, will remain dependent on what Honneth refers to as the "critique of civilization" ("Kulturkritik"). A style of critique which more appropriately reflects the work of Nietzsche than that of Marx, simultaneously divests itself from the field of economic and social reality and from the lived experience of work.

\section{3}

While trying to restore work to its former place of honour, one is confronted with the old approaches in which it played a leading part, such as those found in Marx. Historically, the success of the concept of reification must be explained by the fact that it intended, in a

9 According to Lukács, "reification" (just like "alienation" in the sense it appears in Marx's texts of 1844) seems to find its first expression in the world of work (through the Taylorist organization of tasks), but this empirical priority does not mean an ontological specificity of the experience of work. In fact, for the Hungarian philosopher, the connection between alienation and reification appears to be contingent, for the true idea at work in his reflection is a global concept of "rationalization." See e.g. History and Class Consciousness, chapter 3 , $\S 1$. In this sense, Honneth continues the relativization of the experience of work in the theory of reification. 
new historical and ideological context, to stand for the old philosophy of alienation centred on work. Indeed, in its traditional formulations (for example in the Philosophical-economical Manuscripts of 1844), this philosophy of alienation remained partially metaphysical because it presupposed the loss of a substantial human nature. By comparison, the Lukácsian concept of reification, which, by moving beyond the phenomenon of exploitation, aims to reveal the characteristic field of social pathologies emerging in capitalist modernity, appears more flexible and less essentialist. Instead of starting from a consideration of the human subjectivity which gets lost in some social processes, it more modestly shows the kind of distortion, empirically verifiable, which takes place in the relationship between human beings and objects -a distortion in which the object's inner characteristics cannot be respected.

However, it seems to me that by using the category of alienation, Marx, at his best, answers in advance the aim that Honneth's program sets for itself, and perhaps does so better than a theory of reification can. The aim is to be able to speak about radical negative experiments without reducing them a priori to a lack of distributive justice, or, in a more optimistic way, to a precondition for justified social struggles - experiments which are also central in our current historical situation. More precisely, by speaking the language of alienation one could attach these experiences to a bad appropriation of the object (particularly in work) or (more generally) to the bad appropriation of relationships to the object, an appropriation which asserts that the subject is weakened at the same time as the object is missed..$^{10}$ Around this central image of a bad appropriation of an object, a number of nonLukacsian intuitions were put into play in the critique of pathologies carried out thanks to the vocabulary of alienation. Let me describe some of these intuitions.

- First of all, the problem of alienation initially implies a certain determination of subjectivity. This determination has a very clear phenomenological dimension insofar as it gives us the right to employ terms like discomfort, pain and suffering, and to describe the existential limitations which accompany these existential phenomena. Therefore, in opposition to "reification," which is necessarily limited in this aspect, the concept of "alienation" authorizes us to enter into the thickness of the lived, the vital and the psychic dimensions. In the same way, the problematic of alienation inherited from Marx implies a certain determination of the social which is no less illuminating, I believe, than the problematic of reification. When we evoke alienation, we speak about economic forms which imply a dependence upon anonymous systemic constraints, more concretely involving limitations of freedom and non-conscious constraints upon agency. We speak about the fact that, in modern societies, the systems of action implied by the development of rational action, systems that develop independently of individuals' consciousness and will, may exert effects of alienation upon individuals and orient forms of life and culture in unwanted directions.

For this reason, the term "capitalism" now corresponds to a theoretically articulated concept and not only to a vague and external referent. In short, historically, the discourse on alienation has developed a certain understanding of subjectivity centred around

10 Honneth's critical appreciation of the Manuscripts of 1844, classically centred on calling into question the model of work, is not really sensitive to this dimension of the text. See Struggle for Recognition, chapter 7. 
negative life experiments on the basis of a sociological diagnosis which attaches central (but not inevitably exclusive) importance to the "anonymous systems" of the organization of action, as articulated in Marx's model of capital. Alienation was the concept-symbol of an exchange between a vitalistic phenomenology and a sociology of systemic dispossession of the capacity to act, both of which are absent in a work like Reification because the latter tries -in vain, I believe- to reformulate their intentions within the framework of a partial discourse on human interaction.

Given the above, two possible readings above - a weak and a strong one- can be offered with respect to Honneth's theory of recognition. In the weak reading, the theory of recognition (in the two different forms Honneth has given it to date) can be understood as contributing to reformulate and to reform the contents of the concept of alienation. This reading can be justified by the existence of two continuities. First, one can say that the lack of recognition deprives the individual of certain conditions in his moral and psychic integrity, thus dispossessing him of certain capacities which are normally constitutive of the relationship to oneself. Honneth's notion of a lack of recognition in this sense is very similar to the role played by the concept of alienation in Marx's work. Secondly, one could add that individuals maintain an alienated (=inappropriate and restrictive) relationship with the object when one "does not recognize it," in the existential meaning of the term. In short, speaking about recognition would amount to developing, in a different way, certain ideas formerly wrapped in the too dubious and too broad scheme of "alienation".

The stronger reading, on the contrary, sees the problematic of recognition as constituting only a part of the theory of alienation, which remains philosophically and sociologically more inclusive and more fitting to the phenomena. This reading would rest on the existence of important negative experiences, reflecting social pathologies, which clearly deserve to be interpreted as alienations or as causes of alienation. The point is that these pathologies are not illuminated by the concept of reification and are thus unable to be conceived by means of a theory of recognition. If we rely on the typical topics addressed by a traditional critique of alienation -covering, besides the capitalist conditions of work, the diseases, both somatic and mental, induced by economic constraints, all the way to the ideological deformations induced by the culture industry-, the perspective of intersubjectivism, added to the primacy of the scheme of reification, prevents rather than helps Honneth achieve the task he assigned himself in his last book. This would show a way, after having rediscovered it, to explore a new ground by means of an instrument which proves to be too selective.

However, I am not saying that the strong reading is necessarily the correct one. I would say that it is at least aesthetically plausible, insofar as, by allowing for the reappropriation of objects, topics and ideas which had formerly been conceived and put in perspective thanks to the concept of alienation, it would reinforce the project of a critical theory of the present. This reading suggests that by trying to philosophically purify the concept of the "pathological" we are not necessarily correct in our critique against Marx. After all, we will always need words and concepts to correctly explain and to directly express what it means for a subject to go through experiences which vitally diminish him. Although stimulating, the concept of reification is not necessarily cut out for this task. 


\section{REFERENCES}

Fraser, Nancy and Axel Honneth. 2003. Umverteilung oder Anerkennung? Frankfurt: Suhrkamp.

Honneth, Axel. 1992. Kampf um Anerkennung. Zur moralischen Grammatik sozialer Konflikte. Frankfurt: Suhrkamp.

Honneth, Axel. 2005. Verdinglin chung. Eine anerkennungstheortische Studie. Frankfurt: Suhrkamp.

Honneth, Axel. 2000. "Pathologien des Sozialen. Tradition und Aktualität der Sozialphilosophie. Das Andere der Gerechtigkeit". Frankfurt: Suhrkamp: 11-69.

Honneth, Axel. 2002. "Organisierte Selbstverwirklichung. Paradoxien der Individualiserung". In Befreiung aus der Mündigkeit. Paradoxien des gegenwärtigen Kapitalismus, edited by A. Honneth et alii. Frankfurt: Campus.

Merleau-Ponty, Maurice. 1999. Phénoménologie de la perception. Paris: Gallimard.

Stéphane Haber es profesor asociado de filosofía en la Universidad de Franche-Comté, Francia. Entre sus más recientes publicaciones se encuentran dos monografías, Critique de l'antinaturalisme (Paris: PUF, 2006) y L'aliénation (Paris: PUF, 2007), y un libro editado Habermas et Foucault. Parcours croisés, confrontations critiques (Paris: CNRS Editions, 2006). 